\title{
HUBUNGAN ANTARA SELF EFFICACY DENGAN KESEJAHTERAAN PSIKOLOGIS CAREGIVER DALAM MERAWAT LANSIA SKIZOFRENIA DI RSJ Dr. RADJIMAN WEDIODININGRAT LAWANG MALANG
}

\section{The Relationship of Self Efficacy with the Caregiver's Psychological Well Being Who Taking Care for Elderly Schizophrenia at Psychiatric Hospital Dr. Radjiman Wediodiningrat Lawang Malang}

\section{Roudlotul Jannah $^{1 *}$, Joni Haryanto ${ }^{1}$, Yanis Kartini ${ }^{2}$}

1. Magister Keperawatan, Faculty of Nursing, Universitas Indonesia

2. Universitas Nahdatul Ulama Surabaya

\section{Riwayat artikel}

Diajukan: 8 Juli 2019

Diterima: 28 Maret 2020

Penulis Korespondensi:

- Roudlotul Jannah

- Magister Keperawatan,

Faculty of Nursing,

Universitas Indonesia

roudlotul.jannah-

2017@fkp.unair.ac.id

\section{Kata Kunci:}

self efficacy, caregiver, skizofrenia, lansia, kesejahteraan psikologis

\section{Abstrak}

Pendahuluan : Peningkatan jumlah lansia dengan skizofrenia di dunia berkembang pesat. Satu dari tujuh klien skizofrenia adalah berusia lebih dari 65 tahun. Lansia skizofrenia menimbulkan masalah lebih kompleks terkait penyakit dan proses aging. Beban yang dirasakan caregiver selama merawat pasien akan berdampak terhadap kesejahteraan psikologis caregiver, dan secara tidak langsung akan mengakibatkan rendahnya kualitas hidup caregiver dan rendahanya kualitas perawatan yang diberikan kepada pasien. Tujuan: mengetahui hubungan antara self efficacy dengan kesejahteraan psikologis caregiver dalam merawat lansia skizofrenia. Metode: penelitian ini merupakan penelitian kuantitatif dengan pendekatan cross sectional design. Sampel yang digunakan sebanyak 88 caregiver yang memenuhi kriteria inklusi dan ekslusi. Pengambilan sampel dengan cara systematic random sampling. Analisa data dengan correlation dan chi square dengan tingkat signifikansi $95 \%$. Hasil: hasil penelitian menunjukkan bahwa mayoritas caregiver berusia 26-45 tahun (dewasa) sebanyak 58 responden $(65,9 \%)$, berjenis kelamin perempuan sebanyak 53 responden $(60,2 \%)$, mempunyai tingkat pendidikan menengah sebanyak 37 responden $(42 \%)$, penghasilan kurang dari Rp. 1.851 .083 sebanyak 53 responden $(60,2 \%)$, dengan status kekerabatan dengan pasien adalah anak sebanyak 52 responden $(59,1 \%)$.

Kesimpulan: self efficacy sangat penting dimiliki caregiver, dengan self efficacy baik akan mempengaruhi kesiapan caregiver menghadapi situasi-situasi sulit yang penuh tekanan dan stres selama perawatan sehingga kesejahteraan psikologis caregiver tetap baik meskipun kompleksitas permasalan dihadapi selama merawat lansia skizofrenia.

\section{Abstract}

Background: The increasing number of elderly with schizophrenia in the world is growing rapidly. Abaout one from seven schizophrenic clients is older than 65 years old. Elderly with schizophrenia caused more complete problems related to diseases and aging process. The burden felt by the caregiver during caring for the patient will have an impact on the psychological well-being of the caregiver, indirectly will result in the low quality life of caregiver and the low quality of care provided to the patient. Objective: to determine the relationship between self efficacy and the psychological well-being of caregivers who taking care for elderly schizophrenia. Method: this study is a quantitative study with a cross sectional design. Samples were 88 respondets, taken by systematic random sampling according to inclusion and exclusion criteria. Data were analysis using correlation and chi square with a significance level of 95\%. Results: result of the study showed that the majority of caregivers aged 26-45 years (adults) were 58 respondents (65.9\%), female as many as 53 respondents (60.2\%), had senior high school education levels as many as 37 respondents (42\%), income status less than Rp. 1,851,083 as many as 53 respondents $(60.2 \%)$, relationship with patients was children as many as 52 respondents (59.1\%). Conclusion: Self efficacy is very important for caregivers, with good efficacy will affect the readiness of caregivers to solved difficult situations that are stressful and stressful during treatment so that psychological well-being remains good even though the complexity of problems is faced while providing care for elderly schizophrenia. 


\section{PENDAHULUAN}

Skizofrenia masih menjadi perhatian dunia, begitu juga di Indonesia. Lansia dengan skizofrenia menimbulkan masalah lebih kompleks terkait penyakit dan proses aging (Meesters et al. 2013). Keluarga sebagai caregiver skizofrenia merasakan beban pengasuhan yang tinggi. Peningkatan jumlah lansia dengan skizofrenia di dunia berkembang pesat. Satu dari tujuh klien skizofrenia adalah berusia lebih dari 65 tahun dan jumlah lansia dengan skizofrenia akan meningkat dua kali lipat (Meesters et al. 2013).

Data Riset Kesehatan Dasar (RISKESDAS) tahun 2018 menunjukkan bahwa prevalensi penderita skizofrenia di Indonesia 7,0 per mil. Provinsi Jawa Timur merupakan salah satu provinsi di Indonesia dengan peningkatan jumlah penderita skizofrenia dari 2,2 per mil menjadi 5.0 per mil. Secara global hanya terdapat 0,61 fasilitas kesehatan jiwa rawat jalan setiap 100.000 penduduk dan 17,5 tempat tidur di rumah sakit yang tersedia tiap 100.000 penduduk (WHO, 2015). Data tersebut menggambarkan sebagian besar orang dengan gangguan jiwa dilakukan perawatan oleh keluarganya sendiri di rumah.

Peningkatan jumlah lansia akan mempengaruhi angka beban ketergantungan perawatan, khususnya pada lansia dengan masalah kejiwaan berat (severe mental illness) seperti skizofrenia (Mizuno et al. 2012). Keluarga di negara Asia merupakan caregiver alami yang menyediakan perawatan bagi penderita gangguan jiwa (Stanley et al. 2017) Keluarga membantu kebutuhan klien dengan perawatan medis, memberikan dukungan secara emosional dan mempertahankan haknya dalam menjalani kehidupan sehari-hari (Mizuno et al. 2012)

Keluarga harus mendampingi klien selama 24 jam di setiap hari untuk memberikan dukungan (Jones, 2005). Keluarga juga membantu klien dalam aktifitas sehari-hari, seperti mandi, berdandan, makan, minum obat, dan eliminasi (Maldonado, J.G., Un'zar 2007). Lansia dengan skizofrenia akan menimbulkan masalah yang lebih kompleks terkait dengan rendahnya pemahaman akan kebutuhan yang dibutuhkan lansia skizofrenia disertai dampak penuaan (aging process) seperti penyakit degeneratif, kerusakan fungsi kognitif dan hilangnya fungsi sosial (Meesters et al. 2013). Keberadaan klien skizofrenia dalam keluarga merupakan stresor dan $67,8 \%$ keluarga merasakan berbagai beban (Darwin, Hadisukanto
\& Elvira, 2013). Beban yang dirasakan meliputi beban subjektif seperti perasaan khawatir terhadap status kesehatan penderita, kondisi finansial dan pemenuhan kebutuhan sehari-hari (Ennis \& Bunting, 2013: Hadrys, Adamowski, \& Kiejna, 2011). Sementara beban objektif dialami dalam bentuk penurunan status kesehatan pengasuh keluarga akibat kelelahan selama merawat penderita (Chou et al, 2011).

Dampak akibat tingginya beban pengasuhan yang dialami keluarga menyebabkan tingginya stres keluarga, koping keluarga tidak efektif sehingga menimbulkan kegagalan keluarga dalam merawat klien gangguan jiwa di rumah (McCubbin, 2002). Keluarga yang memiliki anggota keluarga dengan gangguan jiwa (schizophrenia) akan mengalami pergolakan yang besar (Townsend, 2009). Sejumlah penelitian menunjukkan bahwa caregiver keluarga penderita gangguan jiwa berat mengalami tekanan yang signifikan dan memiliki tingkat beban yang tinggi (Chan 2011). Keluarga seringkali merasa cemas dan kebingungan dalam menghadapi penderita skizofrenia, terutama saat penderita kambuh (Suhita et al., 2017). Penyebab $80 \%$ kekambuhan klien skizofrenia adalah ketidakmampuan keluarga dalam mengontrol emosi (Fadli \& Mitra, 2013), masalah stresor dalam keluarga, sehingga kritik terus menerus dari keluarga menyebabkan kekambuhan klien (Amaresha, 2012). Ketidakmampuan tersebut dipengaruhi oleh berbagi stesor, beban perawatan (Darwin, 2013), persepsi negatif atau stigma (Yusuf et al., 2016) dan kurangnya dukungan dari lingkungan sekitar. Hal ini menjadi akar yang mempengaruhi kesejahteraan psikologis caregiver.

Self-efficacy merupakan salah satu kemampuan pengaturan diri individu. Selfefficacy mengacu pada persepsi tentang kemampuan individu untuk mengorganisasi dan mengimplementasi tindakan untuk menampilkan kecakapan tertentu (Bandura, 1997). Baron dan Byrne (2000) mengemukakan bahwa self-efficacy merupakan penilaian individu terhadap kemampuan atau kompetensinya untuk melakukan suatu tugas, mencapai suatu tujuan, dan menghasilkan sesuatu. Di samping itu, Schultz (2011) mendefinisikan self-efficacy sebagai perasaan kita terhadap kecukupan, efisiensi, dan kemampuan kita dalam mengatasi kehidupan.

\section{METODE}


Pada penelitian ini menggunakan desain penelitian kuantitatif dengan pendekataan cross sectional yaitu suatu penelitian yang mempelajari dinamika korelasi antara faktor-faktor resiko dengan efek, dengan cara pendekatan, observasi atau pengumpulan data sekaligus pada suatu saat. Artinya tiap subjek penelitian hanya diobservasi sekali saja dan pengukuran dilakukan terhadap status karakter atau variable subjek pada saat pemeriksaan (Notoatmodjo, 2005).

Populasi dalam penelitian ini sebanyak 108 caregiver yang menemani pasien kontrol ke Poli Psikogeriatri RSJ Lawang Malang. Teknik sampling pada penelitian ini menggunakan probability sampling dengan sampel random sistematik (Systematic Random Sampling) yaitu proses pengambilan sampel, setiap urutan ke " $K$ " dari titik awal yang dipilih secara random, sebanyak 88 responden yang memenuhi kriteria inklusi dan ekslusi. Kriteria inklusi dalam penelitian ini adalah caregiver yang terlibat merawat lansia skizofrenia, hidup serumah dengan pasien $\geq 1$ tahun, berusia $\geq 18$ tahun/ sudah pernah menikah, bersedia menjadi responden dengan menandatangai inform consent. Kriteria ekslusi : tidak kooperatif dan mempunyai riwayat gangguan jiwa berat.

Instrumen untuk mengukur self efficay menggunakan kuesioner modifikasi kuesioner yang dikembangkan oleh Albert Bandura (1995). Kesejahteraan psikologis di ukur dengan menggunakan kuesioner yang dikembangkan dari konsep kesejahteraan psikologis Ryff (1995). Terdiri dari 6 parameter yaitu penerimaan diri, memiliki hubungan positif, mampu mengarahkan tingkah lakunya sendiri, mampu mengembangkan potensi diri secara berkelanjutan, mampu mengatur lingkungan an memiliki tujuan hidup.

\section{HASIL DAN PEMBAHASAN \\ HASIL PENELITIAN}

Dari hasil penelitian ini didapatkan data karakteristik responden sesuai tabel 1, bahwa mayoritas caregiver yang merawat lansia skizofrenia berusia 26-45 tahun (dewasa) sebanyak 58 responden $(65,9 \%)$, berjenis kelamin perempuan sebanyak 53 responden $(60,2 \%)$, mempunyai tingkat pendidikan menengah sebanyak 37 responden (42\%), penghasilan kurang dari Rp. 1.851.083 sebanyak 53 responden $(60,2 \%)$, dengan status kekerabatan dengan pasien adalah anak sebanyak 52 responden $(59,1 \%)$.

Berdasarkan tabel 2 bisa diketahui bahwa caregiver yang memiliki self efficacy dalam kategori baik sebanyak 32 responden (36,4 responden), dengan tingkat kesejahteraan dalam kategori baik 26 responden, cukup 2 responden dan kurang 4 responden. Responden dengan self efficacy dalam kategori sedang sebanyak 33 responden $(37.5 \%)$ dengan tingkat kesejahteraan baik sebanyak 20 responden, cukup 6 responden dan kurang 7 responden. Selebihnya responden yang memiliki self efficacy buruk sebanyak 23 responden $(26,1 \%)$ dengan tingkat kesejahtearaan baik 9 responden, cukup 5 responden dan baik 9 responden.

Tabel 1. Karakteristik Responden ( $\mathrm{n}=88$ )

\begin{tabular}{llcc}
\hline \multicolumn{2}{c}{ Karakteristik Responden } & $\mathrm{n}$ & $\%$ \\
\hline Usia & Remaja $\quad(18-25$ & 8 & 9,1 \\
& tahun) & 58 & 65,9 \\
& Dewasa $\quad(26-45$ & 22 & 25 \\
& tahun) & 88 & 100 \\
& Pra-Lansia (46-65 & & \\
& tahun) & & \\
Jenis & Total & & \\
Kelamin & Laki-laki & 35 & 39,8 \\
& Perempuan & 53 & 60,2 \\
Pendidikan & Total & 88 & 100 \\
& Dasar & 31 & 35,2 \\
& Menengah & 37 & 42,0 \\
& Tinggi & 20 & 22,7 \\
Penghasilan & Total & 88 & 100,0 \\
& <Rp 1.851.083 & 53 & 60,2 \\
& >Rp 1.851.083 & 35 & 39,8 \\
Status & Total & 88 & 100 \\
kekeluargaan & Anak/Menantu & 52 & 59,1 \\
& Cucu/Cicit & 6 & 6,8 \\
& Istri/Suami & 14 & 15,9 \\
& Saudara & 15 & 17,0 \\
& Lain-lain & 1 & 1,1 \\
& Total & 88 & 100 \\
\hline
\end{tabular}

Tabel 2. Hasil Analisis Self efficacy dan Kesejahteraan Psikologis Caregiver

\begin{tabular}{|c|c|c|c|c|c|}
\hline \multirow{2}{*}{$\begin{array}{c}\text { Self } \\
\text { Efficac } \\
y\end{array}$} & \multicolumn{3}{|c|}{$\begin{array}{l}\text { Kesejahteraan } \\
\text { Psikologis }\end{array}$} & \multirow[t]{2}{*}{ Total } & \multirow{2}{*}{$\begin{array}{c}\mathrm{p}- \\
\text { valu } \\
\mathrm{e}\end{array}$} \\
\hline & baik & cukup & kuran & & \\
\hline \multirow[t]{2}{*}{ Baik } & 26 & 2 & $\frac{5}{4}$ & 32 & \\
\hline & $\begin{array}{c}81.3 \\
\%\end{array}$ & $6.2 \%$ & $12.5 \%$ & $\begin{array}{c}100 \\
\%\end{array}$ & \\
\hline \multirow[t]{2}{*}{ Sedang } & 20 & 6 & 7 & 33 & \\
\hline & $\begin{array}{c}60.6 \\
\%\end{array}$ & $\begin{array}{c}18.2 \\
\%\end{array}$ & $21.2 \%$ & $\begin{array}{c}100 \\
0\end{array}$ & $\begin{array}{c}0.03 \\
4\end{array}$ \\
\hline \multirow{2}{*}{ Buruk } & 9 & 5 & 9 & 23 & \\
\hline & $\begin{array}{c}39.1 \\
\%\end{array}$ & $\begin{array}{c}21.7 \\
\%\end{array}$ & $27.3 \%$ & $\begin{array}{c}100 \\
\%\end{array}$ & \\
\hline \multirow[t]{2}{*}{ Total } & 55 & 13 & 20 & 88 & \\
\hline & $\begin{array}{c}62.5 \\
\%\end{array}$ & $\begin{array}{c}14.8 \\
\%\end{array}$ & $22.7 \%$ & $\begin{array}{c}100 \\
\%\end{array}$ & \\
\hline
\end{tabular}

Hasil analisa data dengan uji chi-square didapatkan dengan tingkat kepercayaan 95\%, didapatkan $p$-value $0.034(\mathrm{p}<0.05)$, sehingga bisa 
diketahui bahwa ada hubungan yang signifikan antara self efficacy dengan kesejahteraan psikologis caregiver dalam merawat lansia skizofrenia.

\section{PEMBAHASAN}

Self efficacy sebagai salah satu unsur dari positif belief merupakan unsur yang membentuk keyakinan atas kepastian yang di miliki untuk bisa menjalankan tugas atau menangani persoalan dengan hasil yang bagus (Bandura, 1997). Self efficacy berhubungan dengan kemampuan individu mengendalikan stres. Self efficacy merupakan salah satu kemampuan pengaturan diri individu. Self efficacy mengacu pada persepsi tentang kemampuan individu untuk mengorganisasi dan mengimplementasi tindakan untuk menampilkan kecakapan tertentu (Bandura, 1997). Baron dan Byrne (2000) mengemukakan bahwa self efficacy merupakan penilaian individu terhadap kemampuan atau kompetensinya untuk melakukan suatu tugas, mencapai suatu tujuan, dan menghasilkan sesuatu. Di samping itu, Schultz (2011) mendefinisikan self efficacy sebagai perasaan kita terhadap kecukupan efisiensi, dan kemampuan individu dalam mengatasi kehidupan.

Dalam kasus perawatan penderita lansia skizofrenia self efficacy caregiver berhubungan dengan kemampuannya untuk mengatasi permasalahan, stres maupun pemecahan masalah dalam merawat anggota keluarganya yang menderita skizofrenia. Self-efficacy terbentuk melalui proses belajar dan terbentuk sebagai suatu proses adaptasi dan pembelajaran yang ada dalam situasi yang dihadapinya tersebut. Semakin lama seseorang bekerja dalam hal ini caregiver dalam merawat penderita skizofrenia, maka semakin tinggi self efficacy yang dimiliki caregiver tersebut dalam proses perawatan penderita skizofrenia karena memiliki pengalaman yang banyak dalam proses perawatan selama ini.

Selain faktor lama merawat, faktor lain yang berperan terhadap self efficacy adalah jenis kelamin, usia dan tingkat pendidikan (Bandura, 1997). Mayoritas caregiver dalam penelitian ini adalah wanita, pada beberapa bidang pekerjaan tertentu para pria memiliki self efficacy yang lebih tinggi dibanding dengan wanita, begitu juga sebaliknya wanita unggul dalam beberapa pekerjaan dibandingkan dengan pria. Perempuan lebih dominan dalam pengasuhan anggota keluarga yang sakit (Schneider et al, 2010).

Usia dalam penelitian ini caregiver berada pada rentang usia 26-45 tahun. Self- efficacy terbentuk melalui proses belajar sosial yang dapat berlangsung selama masa kehidupan. Individu yang lebih tua cenderung memiliki rentang waktu dan pengalaman yang lebih banyak dalam mengatasi suatu hal yang terjadi jika dibandingkan dengan individu yang lebih muda, yang mungkin masih memiliki sedikit pengalaman dan peristiwa-peristiwa dalam hidupnya. Individu yang lebih tua akan lebih mampu dalam mengatasi rintangan dalam hidupnya dibandingkan dengan individu yang lebih muda, hal ini juga berkaitan dengan pengalaman yang individu miliki sepanjang rentang kehidupannya.

Tingkat pendidikan caregiver dalam penelitian ini adalah mayoritas berpendidikan jenjang sekolah menengah, self efficacy terbentuk melalui proses belajar yang dapat diterima individu pada tingkat pendidikan formal. Individu yang memiliki jenjang yang lebih tinggi biasanya memiliki self efficacy yang lebih tinggi, karena pada dasarnya mereka lebih banyak belajar dan lebih banyak menerima pendidikan formal, selain itu individu yang memiliki jenjang pendidikan yang lebih tinggi akan lebih banyak mendapatkan kesempatan untuk belajar dalam mengatasi persoalan-persoalan dalam hidupnya.

Self efficacy yang baik mampu mempengaruhi kesejahteraan psikologis caregiver selama merawat lansia skizofrenia. Dalam dimensi penguasaan lingkungan terlihat profil meningkat seiring dengan pertambahan usia. Semakin bertambah usia seseorang ia semakin mengetahui kondisi yang terbaik bagi dirinya. Oleh karenanya, individu tersebut semakin dapat pula mengatur lingkungannya menjadi yang terbaik sesuai dengan keadaan dirinya (Ryff, 1989 dalam Tristiana, 2016).

\section{KESIMPULAN}

Self efficacy sangat penting untuk dimiliki caregiver, dengan self efficacy baik akan mempengaruhi kesiapan caregiver menghadapi situasi-situasi sulit yang penuh tekanan dan stres selama perawatan sehingga kesejahteraan psikologis caregiver tetap baik meskipun kompleksitas permasalan dihadapi selama merawat lansia skizofrenia. Self efficacy bisa terstimulasi dengan peer group support sesama caregiver yang merawat lansia skizofrenia.

\section{DAFTAR PUSTAKA}

Amaresha, A.C. \& Venkatasubramanian, G. (2012) Expressed emotion in schizophrenia: An overview. Indian Jurnal Psychology Medicine, 34 (1), 12-20

Badan Penelitian dan Pengembangan Kesehatan 
(2018) 'Riset Kesehatan Dasar (RISKESDAS) 2018', Laporan Nasional 2018

Bandura, A (1997). Self Efficacy: The Exercise of Control., New York : Freeman

Baron, A.Robert, Byrne. Down Erwin, (2006), Social Psychology. Pearson / Allyn \& Bacon. Pennsylvania State University

Chan, Sally Wai-chi. 2011. "Global Perspective of Burden of Family Caregivers for Persons With Schizophrenia." Archives of Psychiatric Nursing 25(5): 339-49. http://dx.doi.org/10.1016/j.apnu.2011.03.0 08.

Chou, Y.-C.,Fu,L-Y.,\&Lin, L-C. (2011) Predictors of subjective and objective caregiving burden in older female caregivers of adults with intellectual disabilities. International McCubbin, \& Olson, P. (2002) Beyond Family Crisis and Family Adaptation. Springer Publishing, New York.

Darwin, P., Hadikusukanto, G.,\&Elvira,S.D. (2013) Beban perawatan dan ekspresi emosi pada pramurawat pasien skizofrenia di rumah sakit jiwa. Journal of Indonesian Medical Association

Fadli, S.M, \& Mitra (2013). Pengetahuan dan ekspresi emosi keluarga serta frekuensi kekambuhan penderita skizofrenia. Jurnal Kesehatan Masyarakat Nasional, 7 (10), 466-

Jones, J., \& Passey, J. (2005) Family adaptation, coping and resources : Parent of children with developmental disabilities and behaviour problems. Journal on Developmental Disabilities, 11 (1)

Maldonado, J.G., Uri'zar, A.C. 2007. "Effectiveness of a Psychoeducational Intervention for Reducing Burden in Latin American Families of Patients with Schizophrenia." Quality of Life Research.

Meesters, Paul D et al. 2013. "The Care Needs of Elderly Patients With Schizophrenia Spectrum Disorders." The American Journal of Geriatric Psychiatry 21(2): 12937.

http://dx.doi.org/10.1016/j.jagp.2012.10.00 8.

Mizuno, Eriko, Misuzu Iwasaki, Ikue Sakai, and Naotoshi Kamizawa. 2012. "Sense of Coherence and Quality of Life in Family Caregivers of Persons With Schizophrenia Living in the Community." Archives of Psychiatric Nursing 26(4): 295-306. http://dx.doi.org/10.1016/j.apnu.2012.01.0 03.
McCubbin, \& Olson, P. (2002) Beyond Family Crisis and Family Adaptation. Springer Publishing, New York.

Notoadmodjo, Soekidjo. 2012. Metodologi penelitian kesehatan. Jakarta : Rineka Cipta.

Ryff, C. D., \& Keyes, C. L. (1995). The Structure of Psychological Well-Being

Revisited. Journal of Personality and Social Psychology, 719-727.

Ryff, C. (1989). Happines is Everything, or is it? Explorations on The Meaning of

Psychological Well-Being. Journal of Personality and Social Psychology, 1069 - 1081

Suhita, B. M. et al. (2017) 'The Adaptation Model Of Caregiver In Treating Family Members With Schizophrenia In Kediri East Java', Jurnal Ners, 12(37), pp. 74-80.

Schultz, Duane P (2011). A History Modern of Psychology. Canada: Wardsworth. Cencage Learning:

Stanley, Selwyn et al. 2017. "Psychological Distress , Perceived Burden and Quality of Life in Caregivers of Persons with Schizophrenia Psychological Distress, Perceived Burden and Quality of Life in Caregivers." 8237(April).

Townsend, M. C, 2009, Psychiatric Mental Healt Nursing : Concepts of Care in EvidenceBasedPractice (6th ed.), Philadelphia : F.A. Davis

Tristiana, D (2016) Psychological Well Being In Type 2 Diabetes Mellitus

Patients In Mulyorejo Public Health Center Surabaya. 11/2/147-156/2016

Jurnal Ners.

WHO (2015) WHO: Schizophrenia, Fact Sheet 397. Available at: http://www.who.int/mediacentre/factsheets /fs $397 / \mathrm{en} /$.

Yusuf, A. et al. (2016) 'Stigma Keluarga Pasien Gangguan Jiwa Skizofrenia', pp. 8-9. Available at: https://www.researchgate.net/profile/Ah_Y usuf/publication/311910653_Stigma_Kelu arga Pasien_Gangguan_Jiwa_Skizofrenia/1 inks/5861b4e308ae329d61ff35d7/StigmaKeluarga-Pasien-Gangguan-JiwaSkizofrenia.pdf. 
Jurnal Ilmiah Keperawatan (Scientific Journal of Nursing), Vol 6, No 1, Tahun 2020 